\title{
CIBERNÉTICA E EDUCAÇÃO
}

Cibernética é definida como comunicação e controle nas máquinas e animais, entre os quais figuram os seres humanos.

Este é o conceito do matemático Norbert Wiener que reinventou, em 1948, a palavra Cibernética (Kubernetes, em grego) introduzida por Platão, que significa a arte de pilotar navios e, por extensão, a arte de conduzir homens e, em sentido mais amplo, a arte de governar o Estado (Nave Social).

A Cibernética wieneriana, cuja base técnica é a Informática, tem se constituído na fonte de emulação de uma série de termos: informação, entropia, comunicação, controle, feedback, transinformação, robô, multimídia etc.; e de expressões: inteligência artificial, máquinas que pensam, animais sintéticos, edifícios inteligentes, realidade virtual, engenharia genética, redes neurais artificiais, cérebro artificial.

$\mathrm{Na}$ verdade, esses termos e expressões representam a grande marcha dos avanços tecnológicos que, a partir de 1950, foram registrados nas Neurociências, na Ciência da Computação, na Ciência da Mente ou Ciência Cognitiva, com grande participação na área da Educação, às vezes indevidamente. Assim, por exemplo, a informação - termo dos mais usados - considerada como poder, por alguns

\section{O AUTOR}

\section{Oswaldo Sangiorgi}

Professor Doutor do Departamento de Comunicações e Artes da ECA-USP. Coordenador Geral do Centro de Cibernética Pedagógica - CCP. cientistas sociais, deixa de ter esse significado, em valor absoluto, porque o poder não é nada sem o controle (parâmetro cibernético).

Especialmente no campo educacional, a chamada Cibernética Pedagógica, introduzida em 1970 pelo ciberneticista Helmar Frank (Universidade de Paderborn, Alemanha), tem um espectro de aplicabilidade muito grande nos centros avançados europeus, americanos e asiáticos.

A Cibernética Pedagógica possibilita, através de princípios científicos de Comunicação e Controle - portanto cibernético -, otimizar as relações entre dois sistemas: Sistema Docente (S.Do.), aquele que pretende ensinar; e Sistema Discente (S.Di.), aquele que deve aprender; sejam eles constituídos por seres humanos ou máquinas.

Duas grandes vertentes da informática - a multimídia e a realidade virtual - colaboram na produção de softwares educativos que otimizam o binômio ensino-aprendizagem entre os sistemas docentes e discentes nas mais variadas composições: professor/aluno; professor/máquina que aprende; máquina que ensina/aluno; máquina que ensina/máquina que aprende.

Atualmente a Ciência da Mente, pela qual se objetiva a compreensão da mente humana nos processos de aprendizagem, utiliza a informática, através da inteligência artificial (I.A.), para fornecer modelos de máquinas reais ou teóricas que permitem simular a mente humana, particularmente $o$ pensamento. 


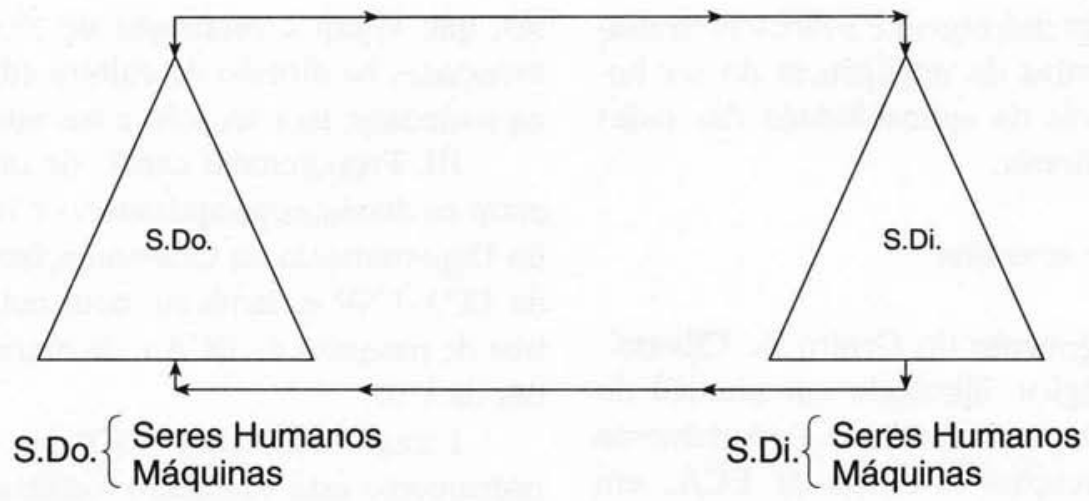

A mais recente tecnologia conhecida como Redes Neurais Artificiais (RNA) representa uma vigorosa ferramenta que procura saber como o ser humano pensa.

Daí a importância do uso de tecnologias cibernéticas informo-comunicacionais na Educação, pois, enquanto a Inteligência Artificial fornece modelos de máquinas que pensam, as Redes Neurais Artificiais apresentam sistemas que aprendem, ou seja, programas de computador que tomam decisões baseadas em experiências já acumuladas.

$\mathrm{Na}$ esteira da chamada globalização, o paradigma educacional, sob o ângulo geográfico, é o de conhecimentos transportáveis, sistematizado por redes, tendo como principal estrutura-suporte a Internet, à qual vem acoplada a Ciberteca ou Biblioteca Virtual que gerencia recursos de informação.

Tanto a educação continuada, destinada às pessoas que já passaram pelas Escolas de Graduação e prosseguem seus estudos, quanto a Educação segmentada em módulos de ciclos, de acordo com os Parâmetros Curriculares Nacionais de 1998, deverão num aspecto globalizante - ser exercitadas, através de um ensino-presencial ou de um ensino a distância, nos respectivos modus operandi: metodologia desenvolvida em salas de aula convencionais ou pelas teleco- municações em salas localizadas em partes diversas do globo terrestre.

O mundo está sem fronteiras. A globalização (de ordem física) pode ser sentida por intermédio da Internet. Nas portas do Terceiro Milênio, em plena época digitalizada, onde os átomos que compõem a matéria estão sendo substituídos por bits 0 e 1 , vive-se a maior interatividade dos meios eletrônicos, que permitem transmitir imagens, sons, textos e animações, simultaneamente.

Nestas condições, estamos praticando a globalização do ótimo, pois estamos enriquecendo, sobremaneira, os conteúdos a serem transmitidos, em especial os especificamente educativos que, no reino da interatividade, exercem um poder de fascínio junto aos estudantes da atual geração, cujas culturas parecem estar se homogeneizando.

\section{CENTRO DE CIBERNÉTICA PEDAGÓGICA - CCP DA ECA-USP}

O Centro de Cibernética Pedagógica da Escola de Comunicações e Artes da USP é um centro de estudos e pesquisas cibernéticas na área da Educação, coordenado pelo professor doutor Oswaldo Sangiorgi. Desenvolve, atualmente, pesquisas na área 
de ensino-aprendizagem e sobre a mensuração quantitativa da inteligência do ser humano, através da aplicabilidade das redes neurais artificiais.

\section{O Centro e seus fins}

O Regimento do Centro de Cibernética Pedagógica, aprovado em reunião do Conselho Departamental do Departamento de Comunicações e Artes da ECA, em 19/09/94, dispõe sobre os objetivos, finalidades, financiamento e patrimônio do Centro, conforme os artigos que seguem.

Artigo $1^{\circ}-\mathrm{O}$ Centro de Cibernética Pedagógica, doravante designado por CCP, vincula-se ao Departamento de Comunicações e Artes da ECA-USP e tem por objetivo:

I. Desenvolver estudos avançados e pesquisas nas interfaces da Cibernética e da Educação, com ênfase nos problemas de natureza Pedagógica e de Ensino-Aprendizagem;

II. Realizar experimentos e estudos da tecnologia informática, por intermédio de suas vertentes Multimídia, Realidade Virtual e Robótica, na pesquisa de materiais instrucionais e educativos, bem como elaborar os respectivos processos de avaliação, através de parâmetros cibernéticos.

Parágrafo Único. O CCP subordina-se à legislação em vigor na USP, na ECA e no CCA.

Artigo $2^{\circ}-$ Para realizar seus objetivos o CCP se propõe:

I. Colaborar na criação de cursos de Pós-Graduação, de Aperfeiçoamento e de Extensão Universitária, onde sejam efetivadas aplicações da Cibernética nos campos de conhecimento científico, humanístico e artístico, de acordo com o Artigo 28, do Regimento da ECA;

II. Participar de programas e projetos de outras instituições nacionais ou estrangei- ras, que visem à promoção de tecnologias avançadas na difusão da cultura cibernética na sociedade, na educação e nas artes;

III. Proporcionar canais de integração entre os docentes/pesquisadores e os alunos do Departamento de Comunicações e Artes da ECA-USP e, também, com outros centros de pesquisa da ECA e de outras unidades da USP.

Páragrafo Único. O CCP que, por este instrumento está vinculado formalmente ao CCA, manterá e ampliará liames, inclusive de assessoria científica de suas publicações, com entidades internacionais.

\section{A constituição do $\mathrm{CCP}$}

Artigo $3^{\circ}-\mathrm{O}$ CCP será constituído por docentes/pesquisadores do Departamento de Comunicações e Artes, dele podendo participar pesquisadores/bolsistas e alunos do CCA.

Artigo $4^{\circ}$ - O CCP será gerido por um Coordenador, designado pelo Conselho do $\mathrm{CCA}$, na pessoa de um professor especialista em matéria de que trata o CCP, integrante dos currículos dos cursos de Graduação ou Pós-Graduação.

Parágrafo Único. O Coordenador indicará, dentre os pesquisadores do $\mathrm{CCP}$, um Coordenador-Substituto.

Artigo $5^{\circ}$ - Ao Coordenador compete gerir os recursos humanos e financeiros do CCP, devendo prestar contas das atividades desenvolvidas em Relatório a ser enviado anualmente ao CCA.

\section{$O$ financiamento}

Artigo $6^{\circ}-$ Para o desenvolvimento de projetos, $\mathrm{o} C \mathrm{CP}$ poderá obter recursos externos à Universidade, de acordo com a legislação vigente na USP, na ECA e no CCA. 


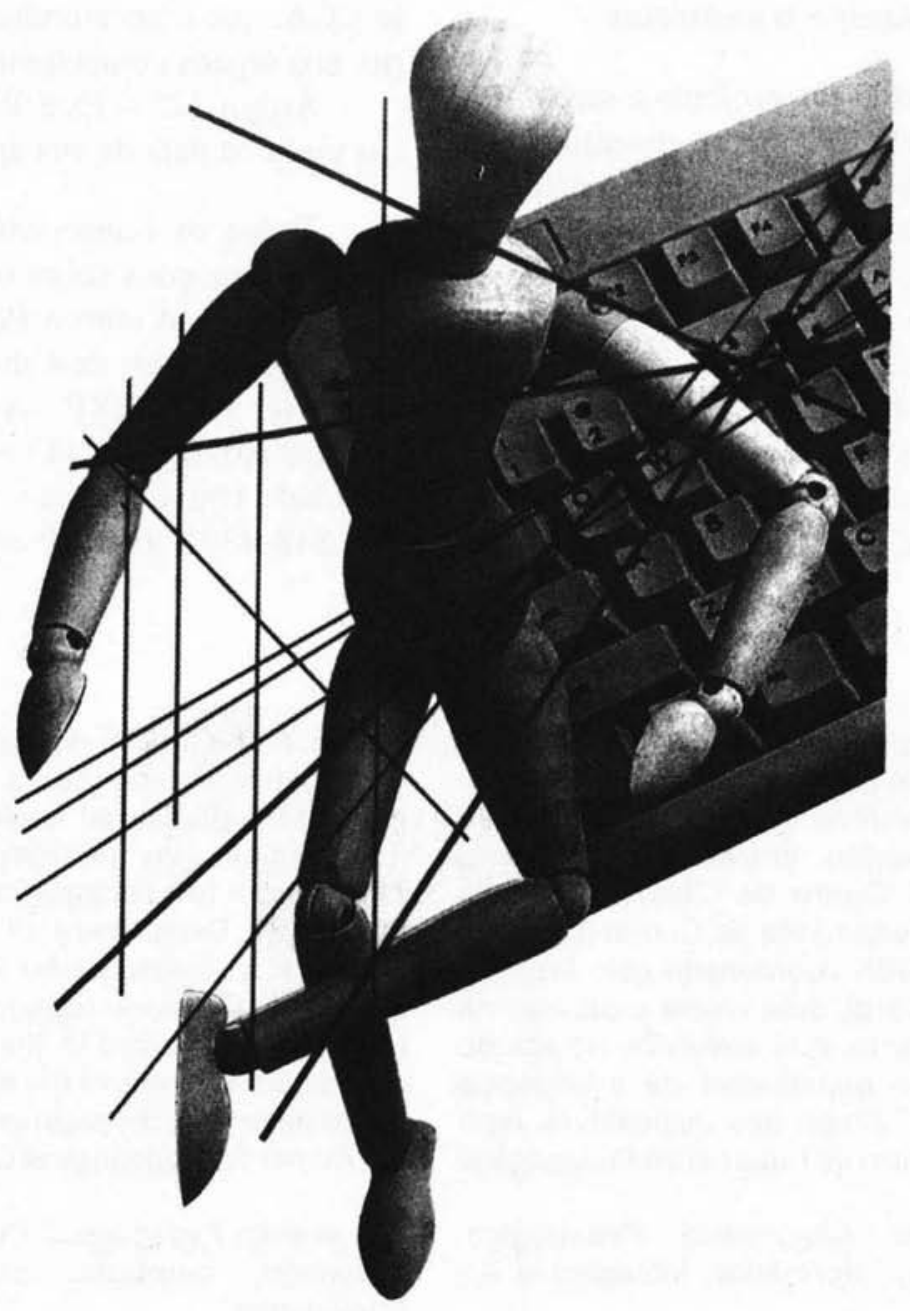

Parágrafo Único. Para cada projeto se fará um orçamento no qual, além das rubricas específicas do mesmo, deverão estar claramente contempladas as disposições do Parágrafo $2^{\circ}$ do Artigo 28, do Regimento da ECA.

Artigo $7^{\circ}$ - Para atender necessidade temporária de excepcional interesse, o CCP poderá, por tempo limitado, utilizar prestação de serviços de pesquisadores e outros auxiliares, estranhos ao CCA, para levar a cabo tarefa específica.

\section{O patrimônio}

Artigo $8^{\circ}$ - O CCA determinará espaço próprio para o bom desenvolvimento das atividades do CCP.

Artigo $9^{\circ}-\mathrm{O}$ CCP utilizará os equipamentos e bens já existentes em sua sede, bem como os que vierem a ser adquiridos de entidades públicas ou privadas, de fomento à Pesquisa.

Parágrafo Único. Caso o CCP seja desativado, todos os seus equipamentos e bens continuarão patrimoniados no CCA. 


\section{Disposições gerais e transitórias}

Artigo $10^{\circ}$ - Os projetos a serem desenvolvidos pelo CCP serão encaminhados ao Coordenador para efeito de análise e emissão de parecer.

Parágrafo Único. No caso de parecer favorável cabe ao Conselho do CCA a sua aprovação final.

Artigo $11^{\circ}$ - Qualquer modificação deste Regimento deverá ser realizada mediante proposta aprovada em primeira instância pelo Coordenador e, em seguida, pe-

Resumo: $\mathrm{O}$ artigo explica o significado de Cibernética bem como os seus usos e aplicabilidades no mundo globalizado, principalmente na educação, através da Cibernética Pedagógica. O Centro de Cibernética Pedagógica do Departamento de Comunicaçōes e Artes da ECA-USP, coordenado pelo Prof. Dr. Oswaldo Sangiorgi, desenvolve pesquisas na área e, atualmente, está envolvido no estudo da mensuração quantitativa da inteligência humana. Trata, ainda, dos dispositivos regimentais do Centro de Cibernética Pedagógica.

Palavras-chave: Cibernética Pedagógica, Redes Neurais, informática, Inteligência Artificial lo CCA, que o encaminhará, caso necessário, aos órgãos competentes.

Artigo $12^{\circ}$ - Este Regimento entrará em vigor na data de sua aprovação.

Todos os interessados em conhecer mais informações sobre o CCP devem entrar em contato com o Prof. Dr. Oswaldo Sangiorgi. Centro de Cibernética Pedagógica da ECA-USP, Av. Prof. Lúcio Martins Rodrigues, $443-2^{\circ}$ andar, sala 5 - Cidade Universitária - SP - 05508-900 Tel: 818-4372.E-mail: osangior@usp.br

Abstract: The article explains the meaning of Cybernetics as well as its use and applications in the globalized world, most especially in education, via Pedagogical Cybernetics. The Center for Pedagogical Cybernetics of ECA-USP's Department of Communications and Arts, coordinated by Prof. Dr. Oswaldo Sangiorgi, develops research in the area and is currently involved in the study of quantitative measurements of the human intelligence. It also deals with the regimental dispositions of the Center for Pedagogical Cybernetics.

Key words: Pedagogical Cybernetics, Neural Networks, computer science, Artificial Intelligence 